\title{
Caring in English: ESP for Nurses
}

\author{
Andrew Finch ${ }^{1}$ \\ ${ }^{1}$ Kyungpook National University, Republic of Korea \\ Correspondence: Andrew Finch, Kyungpook National University, Republic of Korea. E-mail: aef@knu.ac.kr
}

Received: July 29, 2013 Accepted: August 9, 2013 Online Published: August 12, 2013

doi:10.5430/ijelt.v1n1p1 URL: http://dx.doi.org/10.5430/ijelt.v1n1p1

\begin{abstract}
This paper explores the issue of practitioner-patient communication in the English as a Foreign Language (EFL) context, when the healthcare worker's first language is not that same as that of the patient. In the English as a Second Language (ESL) setting of countries such as the USA and the UK, this issue concerns international graduate students, physicians, and nurses, who need to acquire the technical language of Medical English for their professional qualifications, along with the psychosocial language of physician-patient relationships. In the EFL setting of countries such as Korea the situation is different, but the need for health staff to be able to communicate with English-speaking patients is increasing, in addition to the need to read professional publications printed in English. This paper suggests therefore that due to factors such as international mobility, globalization, and the spreading of English as a Lingua Franca (ELF), medical colleges and nursing colleges in EFL countries should go beyond the 'conversation English' paradigm and offer special Medical English programs for pre-service and in-service healthcare personnel. Furthermore, the curricula of these programs should take a humanistic, patient-centered, task-based approach, promoting and developing sensitive counseling skills in English, in addition to teaching the specific vocabulary and lexis of physician-patient interaction.
\end{abstract}

Keywords: communication, language, education, empathy

\section{Introduction}

Regardless of differences in national health systems and other, more cultural factors, healthcare around the world is characterized by the need for caring, sensitive, communication, and the establishment of mutually respectful relationships between the medical practitioner and the patient. As Tan Jia Xing points out:

Communication is crucial in fostering and maintaining healthy relationships. It is absolutely essential especially for nurses, as they not only care for the physically ill, but also look after the emotional well being of their patients. Unfortunately, it is largely taken for granted these days. (Tan Jia Xing, 2009, p. 35)

Just as the English Language Teaching (ELT) profession has progressed from teacher-centered behaviorism to student-centered teaching and a socio-cultural approach, so the medical profession has moved on from physician-centered consultation and has come to recognize that health-worker/patient relationships are extremely complex and dynamic. Tan Jia Xing's final sentence (above) highlights the fact that health workers are frequently overwhelmed with excessive workloads and have little time to interact, but nevertheless, it is generally agreed that sensitive listening, counseling, and understanding perform a "central clinical function" (Stewart, 1995, p. 1432), which can facilitate and enhance the treatment-recovery process. Patients are not robots or Pavlovian dogs, with predictable responses to prescribed stimulations. They do not always do what they are told in terms of taking medicine or following a course of treatment, and their reaction to consultation and treatment is often controlled by psychological factors. Patients are human beings, with their own world-views, seen through the subjective lenses of perceptions, opinions, and beliefs. These personal 'truths' determine how they react to illness, treatment, and therapy, and if they are different from the doctor's or the nurse's 'truths', diagnosis and treatment can be impaired by misunderstanding and even rejection. This paper therefore explores the language of practitioner-patient communication and relationships, with a focus on Medical English, suggesting that doctors and nurses need to be psychologists and counselors, as well as experts in their fields, and that EFL Medical English programs need to provide language and strategies for these psychosocial and professional requirements.

The need for caring, therapeutic communication has been the subject of many publications (Henley, 2011; Morasch, 2004; Richards, 1990; Stewart, 1995; Wachtel, 2011) concerned with effective and sensitive communication between 
patients and healthcare professionals who share the same mother tongue (English). However, The growth of English as a Lingua Franca (ELF), English as an International Language (EIL), and English as a Global Language (EGL), along with increased mobility of populations and opportunities for study and employment in English speaking countries, has led to a greater diversity of medical personnel in those countries, and to a need for multilingual medical practitioners.

One aspect of this new field in the English as a Second Language (ESL) context is concerned with medical staff working in an English-speaking country, but using English as their second language. Van Zentan (2011) states that "Currently, approximately $25 \%$ of physicians in training and in practice in the United States are graduates of international medical schools and approximately $75 \%$ of these ... self-report a native language other than English" (2011, p. 77). Such graduates face the task of functioning effectively in an English-speaking medical environment, with all its jargon and technical language, in addition to acquiring appropriate therapeutic conversation skills in English, in a culture that is different from the one in which they grew up. A second aspect of ESL Medical English concerns the patients. Many communities in English-speaking countries consist of immigrant families, in which the new immigrants and the elders still use their native language. In this case, it is necessary either to: i) provide translators in clinics and hospitals; ii) employ medical personnel who are fluent in English and the relevant 'foreign' language; or iii) include basic doctor-patient language in ESL curricula for immigrants applying for citizenship.

In terms of English as a Foreign Language (EFL), the need for Medical English applies to countries in which the first language is not English, but the healthcare professionals need to use English in order to read professional journals, attend international conferences, communicate with international colleagues, and treat English-speaking patients who are visiting, residing, or doing business in the country. The study of Medical English in this setting has previously been self-directed or highly specific and academic, with the goal of studying and working abroad. However, EFL countries such as Korea are now embracing globalization, requiring children to study English from elementary school, and welcoming foreign companies, foreign schools, and overseas universities into the country to set up local branches. In this situation, it is inevitable that domestic health institutions will experience a growing demand for medical English and for effective physician-patient communication in that language. Rather than the traditional conversation-English courses therefore, there is an increasing need for English for Special Purposes (ESP) courses in nursing colleges. In addition to teaching the vocabulary and phraseology of anatomy and general health, these courses should enable nurses and other medical staff to perform basic clinical functions in English and should also develop the ability to give counseling and empathize with the patients in English. In this case, role-plays, discussions, problem solving, non-verbal language, and case studies would be important parts of the curriculum.

It is interesting to note that Korea is already experiencing a "baby boom of mixed children" as "hundreds of thousands of foreign women have been immigrating in recent years," so that "nurses say that they have had to learn how to say "push' in four languages" (Fackler, 2009). In this situation, nurses need to be multilingual, rather than bilingual. However, English being a lingua franca across Asia and Europe, it will be sufficient at present if they can communicate effectively in English.

\section{Literature Review}

Before examining how an ESP curriculum might address the need for promoting communicative competence in medical English, this section describes the current situation in greater depth, looking at calls for therapeutic communication in general and for counseling skills in English in particular. While much of this literature is about English-English interaction, the issues apply equally, if not more so, in ESL and EFL situations.

Wakeford (1983) confirms that the problem of doctors being "unable to communicate efficiently with their patients and colleagues" (p. 233) has been well documented. Thus, Ley (1983) describes communication failures as leading to less than $50 \%$ of patients following medical advice. Other studies report that the words doctors use even between themselves can be ambiguous, and "the main consequence of faulty interviewing must be inadequate or even wrong diagnosis learning to wrong treatment" (Fletcher, 1979, cited in Wakeford, 1983, p. 233). Richards (1990) points out that the British Medical Journal regularly receives letters about "a perceived failure of the doctors concerned to communicate adequately and show that they cared" (1990, p. 1407). She gives a number of examples, including the following:

One woman with advanced neurological disease sent a letter last month expressing her "distress and isolation ... and the painful, humiliating experience" of having her early neurological symptoms and signs dismissed (as psychogenic). (Richards, 1990, p. 1407)

Other letters relating to the treatment of chronic incurable disease express "anger and disillusionment about doctors' 
interest falling off once the disease is diagnosed" (ibid), and Richards quotes a neurologist on this topic: "Students must not be biased against palliative treatment such as physiotherapy, occupational therapy, counseling, and supportive psychotherapy" (ibid). In all these fields, practitioners need to be carers, counselors, advisors, and even mentors. Thus, Hwa-jin Lee (2008) examines the need for polite and courteous language on the part of nurses in cancer units, focusing on appropriate language and behavior and suggesting polite language strategies for effective nursing conversations with cancer patients:

1. greeting before and after nursing intervention,

2. giving emotional support (consolation, sympathy, summarizing the patient's words, complimenting, humor when the patient is exhausted and tired and when the patient's mood is changed),

3. using open questions and indirect questions (getting agreement and giving choice),

4. talking to patients about the results, after nursing intervention,

5. using polite expressions and familiar personal titles. (Hwa-jin Lee, 2008)

Hwa-jin Lee also points out that nurses in Korea are exceptionally busy and stressed, As a result they have very little time to talk with patients and impolite behavior on the part of nurses in cancer units can result through: i) using too much medical terminology; ii) repetition of direct speech; and iii) task-oriented conversation (interrupting and cutting off the patient's speech) (Hwa-jin Lee, 2008). Morasch (2004) also draws attention to the inappropriate use of medical jargon and the resultant confusion and misunderstandings when doctors and nurses perform the following actions:

1. Using medical abbreviations, such as telling a patient they can have a medicine PRN.

2. Using overly specific anatomical descriptions, such as asking a patient if she has pain in the upper right quadrant.

3. Using basic descriptions with inadequate context, such as telling a patient a test result is positive, which might be good or bad, depending on the circumstances and test administered.

4. Using words commonly understood by health care professionals that aren't as well known to patients, as in telling a patient his "mass is benign".

5. Using case descriptions to substitute for personal nouns, such as referring to the patient in room 4-07 as "the gallbladder". (Morasch, 2004, p. 4)

Stewart (1995) categorizes communication difficulties under three headings: i) problems of diagnosis; ii) a lack of patient involvement in the discussion; and iii) the inadequate provision of information to the patient, and shows that these three categories are responsible for a significant lack of effectiveness in treatment:

Studies have shown that $50 \%$ of psychosocial and psychiatric problems are missed, that physicians interrupt patients an average of 18 seconds into the patient's description of the presenting problem, that $54 \%$ of patient problems and $45 \%$ of patient concerns are neither elicited by the physician nor disclosed by the patient, that patients and physicians do not agree on the main presenting problem in 50\% of visits and that patients are dissatisfied with the information provided to them by physicians. These studies point to the conclusion that problems in physician-patient communication are common and worthy of our attention. (Stewart, 1995, p. 1424)

Stewart's findings also highlight the subjective nature of doctor-patient consultations, so that it comes as no surprise that her recommendations for future research include a call for qualitative studies: "because communication is an interactive process, qualitative studies would be particularly helpful. Shared decision making leading to agreement between patient and physician is one example of an interactive process that requires full description of the kind that is possible only in qualitative research approaches." (p. 1432). This call has been taken up by researchers such as Schmidt (2010), and various qualitative studies in Korea from 1989 to 2011 have been summarized by Kim, Hwang, \& Shin (2011). These studies are all concerned with shared-language interactions however (L1 to L1), and it seems likely that there is an even greater danger of communication problems (and therefore diagnosis or treatment errors) occurring in multilingual and cross-cultural situations.

Such dangers can be further illustrated by extending the qualitative approach into a more anthropological examination and delving into the humor-related folklore of doctor-patient relations. Just as proverbs represent a collective cultural and practical wisdom that has grown over the ages, humor encapsulates that collective consciousness in a different manner, highlighting the relevant issues in a way that is telling, yet inoffensive. This part of the literature review therefore presents some examples of the "Doctor, doctor" genre of jokes that has evolved in 
English-speaking countries. Such jokes can be analyzed in terms of psychology, philosophy, linguistics, sociology, history, and literature, but they are offered here as indicators of problems of miscommunication and power-imbalance, as seen from the perspective of the patient - someone who does not understand medical jargon, but has a problem which he/she is putting before the doctor for "expert" consideration. The aim of presenting these jokes is to highlight the problems that have appeared in such consultations over numerous generations and also to derive from them a list of issues and situations to be considered when making an ESP curriculum for Nursing English in the EFL context.

The first of these examples illustrates the stereotypical doctor-patient interaction, with the patient presenting a problem and the doctor producing an instant diagnosis and prescribing an action from his/her elevated position of power and authority:

Patient: Doctor, doctor, I've swallowed a pen. What shall I do?

Doctor: Use a pencil. (Adapted from Regan, 2007, p. 26)

In this simulated exchange, the doctor has no concern for the patient as a human being and focuses solely on the surface problem, providing a solution that satisfies his/her need to dispense with the problem as quickly as possible, but failing to identify with and react to the emotional and affective needs of the patient. As Henley points out, "We have to start seeing medicine in terms of what ill people need. We have to get away from the provider-centred ${ }^{1}$ approach that 'Doctor knows best."' (2011).

The second and third examples make a further telling comment on this need for expediency, with the doctor exhibiting complete disregard for the feelings of the patient, and dismissing non-physical, psychological, or psychosomatic ailments as unworthy of his/her attention. Such treatment not only fails to explore the symptoms and underlying causes, but also threatens to make the problem worse:

Patient: Doctor, doctor. Everyone keeps ignoring me.

Doctor: Next, please!

Patient: Doctor, doctor. Everyone thinks I'm a liar.

Doctor: I don't believe you. (Regan, 2007, p. 10)

As we can see, there is no attention to counseling skills in these jokes, and we are presented instead with a professional who is probably tired or overworked, having to deal with many different patients in a session, and endeavoring to 'get through them' as quickly as possible. Rather than attempting to (or having enough time to) interact with the patient and explore affective, situational, attitudinal and perceptual aspects, the practitioner reacts in a stimulus-response manner, taking the patient's words literally and dismissing him/her as soon as the diagnosis is made.

This one-sided attitude continues in the next example, in which the doctor simply issues a command from his/her position of authority, playing the role of all-knowing expert:

Patient: Doctor, doctor, I think I am a pair of curtains.

Doctor: Pull yourself together. (Adapted from Regan, 2007, p. 3)

In this case the patient and the doctor completely disagree on the nature of the problem (cf. Stewart, 1995) and the patient's attempt to describe the psychological nature of his/her problem is peremptorily cut off, through the use of an idiom ("pull yourself together") that would be meaningless in an EFL context. Despite the fact that "the patient is potentially the biggest asset to clear and effective communication" (Morasch, 2009, p. 9), this dialog is far from the participative democracy of Henley (2011) and Stewart (1995), and illustrates the traditional physician-centered approach that excludes the very people who need to be helped:

We have to see patients as people, not collections of diseases. ... it's about the services patients actually need, not those that doctors think they do. The focus has to be: what does this person need to get well, and to stay well. (Henley, 2011).

In all the examples so far, it can be seen that the psychosocial and psychiatric problems have been missed and the full extent of the patients' concerns have neither been recognized nor elicited by physicians eager to provide a cut-and-dried diagnosis (cf. Stewart, 1995). This tendency is also present in the next example, which highlights a mechanistic, cause-and-effect view of treatment and a reliance on medicine rather than counseling.

Patient: Doctor, doctor. I think I'm a bell.

Doctor: Take these pills and if they don't work, give me a ring. (Adapted from Regan, 2007, p. 3) 
As Henley comments, the National Health Service in the UK is "a disease service rather than a health service. It's trying to offer a pill-based solution rather than adapting its services to a new reality" (Henley, 2011).

Finally, in the last of these examples taken from the wealth of doctor-doctor jokes available online and in various books (e.g. Young, 2011), the doctor shows a willingness to engage with the patient instead of simply prescribing a one-off solution. However, the point of this joke is that the doctor is not skilled in elicitation and counseling, and relies on a stock phrase in his/her attempt to elicit information. As a result, the conversation breaks down almost before it has begun:

Patient: Doctor, doctor, I think I'm losing my memory.

Doctor: When did you first notice this?

Patient: Notice what? (Adapted from Regan, 2007, p. 43)

These jokes also highlight the low-context nature of interactions that take place in the second or foreign language, and which can be confusing for native speakers, who are used to high-context language. This distinction can easily be overlooked when all the participants in an interaction are (apparently) using the same language, and such oversights can quickly lead to misunderstandings and even cause offence. High-context language is typified by hidden assumptions, double meanings, coded information, extra 'spam' information, redundancy, slang, and dialects, and L1 users tend to reduce or omit day-to-day language in favor of idioms, non-verbal language and differences in stress and intonation, producing interactions that can be extremely confusing to L2 speakers. Phoebe (in the TV series Friends) is particularly good at exposing the characteristics of high/low-context language.

Rachel: Has anyone seen my engagement ring?

Phoebe: Yea, it's beautiful. (Friends, Episode 102)

While watching this episode, we can see from Rachel's actions (non-verbal language) and from her intonation and stress (voice) that she has lost her ring and is frantically searching for it. However, Phoebe interprets her words literally. This is a key characteristic of low-context English - words 'mean what they say.' Low-context language is characterized by pure information transfer, with an absence of hidden meanings, idioms, slang, and dialects. In other words, low-context language is all about 'saying what you mean', whereas high-context language goes behind and beyond explicit meaning. It goes without saying that native speakers of English looking for medical treatment in an EFL setting will tend to confuse Korean L1 speakers through their use of high-context English, so that an ESP curriculum for nurses will need to include strategies for dealing with such patients.

\section{Towards a Nursing English Curriculum}

The preceding review of the academic and anthropological literature situation has shown not only that there is a need to teach Medical English and Nursing English to pre-service and in-service healthcare workers in both ESL and EFL settings, but also that the curricula of the courses should promote a humanistic, patient-centered approach to diagnosis, treatment, and aftercare. The need for such an approach is recognized by the General Medical Council (GMC) of the UK, which states that medical students should be taught to "communicate clearly, sensitively, and effectively with patients and their relatives and with fellow practitioners" (Richards, 1990, p. 1407). While the GMC does not prescribe how such communication should be taught, it is significant that a number of Medical English textbooks have appeared recently (Allum \& McGarr, 2008; Bosher, 2008; Glendinning, \& Howard, 2007; Hull, 2010; Lu \& Corbett, 2012; McCullagh, 2008; Parkinson, 2004), in addition to a variety of Medical English programs becoming available in the ESL environments of the USA and the UK.

In this context, Wakeford (1983) describes a study conducted in the U.K. by Pendleton and Wakeford (1979), in which it was found that training in communication skills and psychosocial skills can be beneficial and effective. Their study produced five main findings:

1. Training in communication skills can be carried out effectively in a medical school without a lot of time involvement. It is compatible with the acquisition of basic clinical skills and can be carried out at the commencement of the clinical training of the students.

2. Training need not consist of modelling the students' behavior on the competent behavior of an "expert". Modelling is useful when the students have very little interpersonal competence but it raises problems of congruence when any individual is asked to mimic the behavior of another individual.

3. Training can be effective for all students, irrespective of their initial level of interpersonal competence. 
4. Medical students find training in interpersonal skills both useful and enjoyable adjuncts to training in clinical skills.

5. Evaluation of training needs to be extensive. (Wakeford, 1983, p. 241)

These findings show that medical staff members need training in caring consultation methodology and benefit from taking courses in medical English and interaction skills. This is significant, since Hasler (1983) has shown that many trainers still believe that health personnel do not need such training, and that empathetic communication 'comes naturally' to them as human beings and as language users. ${ }^{2}$ Such healthcare trainers often concentrate on clinical aspects of the consultation, such as whether a physical examination was made appropriately, or if the right antibiotic was prescribed, rather than paying attention to the psychosocial and affective state of the patient and the nature of the interaction. As Hasler points out, it is necessary to provide re-training courses for such trainers, since 'Until they have learnt the necessary techniques, the trainer and trainee will invent various reasons why the exercise is a waste of time" (Hasler, 1983, p. 256).

There is a similar need for awareness and open mindedness on the part of the English-language trainers in the EFL context. Nursing English is not generally offered as a subject in nursing colleges in Korea and there is a shortage of teaching materials in this field, though basic communication courses are available. Hwa-jin Lee (2011) conducted a review of such courses in nursing colleges in six areas of Korea, and found that they were usually given to Freshmen or Sophomore students and had two main aims: i) communication for forming therapeutic relations with patients; and ii) common principles of communication. Lessons usually took place once a week over a 15- or 16-week semester and lasted for one to three hours. Students learned about exploration of the ego and basic communication skills and the teaching methodology usually relied on small group discussions. The main problems identified by Hwa-jin Lee in these mother tongue mediated courses were that the communication taught was neither practical nor clinical and the communication situations were limited, so that students did not learn specific communication language and counseling skills. Having identified these problems, Hwa-jin Lee moves on to suggest a series of maxims and strategies, based on her own qualitative conversational analysis of interviews with nurses, and Grice's theory of logic and conversation (1975). Although her findings relate to L1 communication, Hwa-jin Lee's suggestions (Tables 1 and 2) offer a practical foundation for English for Specific Purposes (ESP) programs that attempt to describe and rehearse suitable language (vocabulary, phrases) and conversational strategies for Korean nurses caring for English-speaking patients.

Table 1. Conversational maxims and strategies, based on Grice (1975), as cited in Hwa-jin Lee (2011. p. 249)

\begin{tabular}{ll}
\hline Maxims & Strategies \\
\hline Quality & Try to make your contribution one that is true \\
& - Do not say what you believe to be false \\
& - Do not say that for which you lack adequate evidence \\
Quantity & Give the right amount of information \\
& - Make your contribution as informative as required \\
& - Do not make your contribution more informative than is required \\
Relevance & Make your contribution relevant \\
& - Be relevant \\
Manner & Be perspicuous \\
& - Avoid obscurity of expression \\
& - Avoid ambiguity \\
& - Be brief \\
& - Be orderly
\end{tabular}


Table 2. Nurses' question and explanation strategies for effective communication, based on Grice (1975), as cited in Hwa-jin Lee (2011, p. 249)

\begin{tabular}{lll}
\hline $\begin{array}{l}\text { Classification } \\
\text { Maxims }\end{array}$ & Question strategies & Explanation strategies \\
\hline $\begin{array}{l}\text { Quality } \\
\text { Quantity }\end{array}$ & Asking what you believe to be true & $\begin{array}{l}\text { Giving the facts you know } \\
\text { Aiving the right amount of } \\
\text { explanations } \\
\text { Asking single questions }\end{array}$ \\
Asking optimistic questions & \\
Relevance & Asking on the same themes & Giving the relevant explanations \\
Manner & Using clear expressions & Using clear expressions Explaining \\
& Asking in an orderly way an orderly way Verifying \\
& Verifying answers & understanding \\
\hline
\end{tabular}

These maxims and strategies provide a useful grounding for nurses trying to communicate meaningfully and clinically with English-speaking patients. However, their use is general and non-specific. When deciding on theme-based chapter headings in a projected EFL Nursing English textbook, the following list of situation-based topics would be more appropriate, though it would need to be extended to include the problem of helping international patients to deal with form-filling, health insurance, and payment of hospital fees:

Patient admission

Respiratory problems

Wound care

Diabetes care

Medical specimens

Medications

Intravenous infusions

Pre-operative patient assessment

Post-operative patient assessment

Discharge planning (based on Allum \& McGarr, 2008).

Wakeford (1983, p. 240) also offers some syllabus considerations, suggesting a number of skills that should be covered, along with the desired impressions that should be created in the mind of the patient (Table 3 ).

Table 3. Syllabus considerations for a Nursing English curriculum, based on Wakeford (1983, p. 240)

\begin{tabular}{ll}
\hline Required skills: & Impressions to be created: \\
\hline Beginning & Warmth \\
Questioning & Confidence \\
Listening & Involvement \\
Regulating & Effectiveness \\
Coping with the patient's feelings & \\
Clarifying & \\
\hline
\end{tabular}

Having combined these topics in a theme-based and skills-based, situational framework, a task-based approach in each chapter could present technical and interactional language input (vocabulary, appropriate phrases, dialogs, etc.), along with integrated reading, listening, speaking and writing activities in a content-based setting (the human body, medical supplies, taking medicine, preparing for treatment, visiting hours, appointments, etc.), taking medical 
situations and terminology as the content of every assignment (discussion, role-play, survey, report etc.). In this situation, meaningful vocabulary and conversational phrases would be learned, rehearsed, and reviewed, with the aim of developing effective interactional strategies that would enable healthcare staff to perform their clinical, psychosocial and psychiatric tasks in English. Dialogs could be modeled on authentic situations that have arisen or are expected to arise in the EFL context, and counseling skills learned in English would be transferrable to mother tongue situations. The dialog that Tan Jia Xing (2009, p. 35) offers is a good example of the sort of content-based dialog that could be incorporated into each chapter, developing the theme of the chapter and presenting students with a communication problem to be solved sensitively, compassionately, and effectively - in English.

Nurse: Mr. Tong, is there something bothering you?

Mr. Tong: No. Why don't you just leave me alone...

Nurse: Is that what you really want? To be left alone?

Mr. Tong: Well, isn't that what your nurses have been doing to me anyway? I can tell they all don't want to care for me.

Nurse: What do you mean by that?

[Suzie remains standing at the foot of the bed]

Mr. Tong: They take such a long time to answer my call bell and seem to be ignoring me most of the time!

Nurse: Mr. Tong, I think you're just thinking too much. I'm sure they care, but they're simply too busy, so there's really nothing to worry about. Well, I do have lots of work waiting for me, but I'll come back and talk to you soon okay? [Suzie smiles and leaves.] (Tan Jia Xing, 2009, p. 35)

Such dialogs could be used as models for student-designed group role-plays, and problem-solving activities could also be offered in each chapter, inviting students to find appropriate and caring ways of dealing with predictable situations. Post-activity discussion could then investigate the problems, derive strategies for dealing with them, and present suitable vocabulary and expressions to be used in similar instances. For example:

An English-speaking patient has just been treated in the emergency room. He was in a minor car crash and is suffering pain in his neck and his legs. You need to admit this patient to the hospital. Try to find out his name, address, place of work (if he has one), and contact details of his next of kin and a Korean friend or relation. You should also talk to him about how he feels and find out if he has any special needs (allergies, medication, etc.).

A Vietnamese woman comes to the emergency room at 3 am in the morning, with her little boy. She does not know Korean, but she speaks English as her second language. You need to talk with her and find out why she has visited the emergency room. Find as many details as you can and calm her down.

A foreign businessman has come to the hospital for a checkup, paid by his company. He has a checkup form, but he doesn't know how to fill it in. He also doesn't know what to do. Perform a role-play of this situation, with the businessman and the nurse. (The Korean checkup form is on the same page of the textbook.)

An effective addition to textbook study and student role-plays would be to emulate Guy's Hospital in the UK by employing actors to play the parts of patients and their relatives. "Students are recorded on videotape as they take histories, counsel patients, break bad news, and so on, and the video is then used in group discussions" (Richards, 1990, p. 1407). The professors and actors in such programs would need to be bilingual, but this sort of problem is rapidly being solved as professionals gain qualifications abroad and English becomes more and more the language of professional communication.

It is not the intention of this paper to give examples of second-language medical situations and appropriate language to be used in them, nor is it the intention to give a list of appropriate phrases and vocabulary to be used in Nursing English programs. Instead, the reader is referred to Allum \& McGarr (2008) and other ESL Medical English and Nursing English textbooks that provide a sound ESP framework that can be adapted to the EFL context. There are also a number of Internet sites such as http://www.hospitalenglish.com, and http://www.englishmed.com, which provide a wealth of teaching and learning materials. The goal of this paper is to identify the need for pre-service and in-service Medical English courses in EFL countries and to call for a task-based, humanistic approach to the teaching of Medical English and Nursing English in Korea and similar countries, helping physicians and nurses to interact with their patients as partners in the healing process.

\section{Conclusion}

In the post-modern world of transcontinental mobility, touch technology, satellite communication, globalization, and 
ethnic diversity, the Asian Tiger countries (Hong Kong, Singapore, Taiwan, and Korea) have evolved into advanced, high-income economies, providing models for the up-and-coming Tiger Cub Economies of Indonesia, Malaysia, the Philippines, and Thailand. As a consequence, they have attracted a great influx of international trade, with many foreign businesses setting up branches in their countries. Universities and international schools from America and Europe have also been drawn to these countries, due to the thriving market for English-medium education and internationally accredited qualifications that these institutions offer. A further result of the 'economic miracle' is that the tourist industry is successfully attracting visitors to experience its culture and many international students are deciding to study in S. E. Asia, while job-seeking visitors are eager to settle in the Tiger countries and benefit from their prosperity. Thus, while Korea remains one of the most heterogeneous countries in the world, it is evident that the number of visitors and temporary residents is sharply increasing. The number of foreigners in the country was $2.2 \%$ in 2009 and there are predictions that this number may rise to $5 \%$ by 2050 (Koreabrand.net, 2010). According to Wikipedia, $14 \%$ of all marriages in South Korea in 2005 were marriages to foreigners.

In this situation, it is increasingly likely that doctors and nurses, especially those in the big cities, will be confronted with patients who do not speak Korean, but who speak English, either as a first language (teachers, diplomats, bankers, traders, tourists, business-people, etc.) or a second language (migrants, mixed-marriage spouses, Asian business-people, conference visitors, etc.). These patients will find it difficult to communicate their problems effectively and will need sensitive attention in order to achieve a correct diagnosis and effective treatment. Thus, the need for well-constructed Nursing English programs is becoming more and more crucial. This paper therefore suggests that pre-service and in-service tuition could be offered in Nursing Colleges, and that these courses would go beyond the normal "conversation English" paradigm, focusing instead on interaction skills, counseling skills, and the specific language needed to care for these people.

As Tan Ji Xing points out, "therapeutic communication skills are essential for nurses to promote healing in patients, but also the physical and emotional well being of their patients." This is a complex and difficult task, especially when nurses have little time to interact, due to their tight schedules and burden of work. In addition, patients are often suffering pain, discomfort or loss, while the rapid turnover of patients can lead to a loss of identity in those that remain (Richards, 1990, p. 1407). These problems are even more difficult to solve when the nurses and patients have different mother tongues. However, it must be remembered that effective caring and communication are interdependent: "You cannot hope to communicate effectively if you do not care about the person on the receiving end." (Morrison \& Burnard, 1997, p. 177). Hence, it is vital that nurses are given the linguistic and psychosocial tools to care for their patients in order to facilitate therapeutic communication in the EFL situation. Finally, it must be remembered that "we nurses are people too" (Ward, 2009), and that effective English communication courses should respect the needs of the nursing practitioner as well as the patient.

\section{References}

Allum, V., \& McGarr, P. (2008). Cambridge English for nursing (Pre-intermediate and Intermediate). Cambridge: Cambridge University Press.

Bosher, S. (2008). English for nursing: Academic skills. Michigan: University of Michigan Press/ESL.

Fackler, M. (2009). Baby boom of mixed children tests South Korea. New York Times: Asia Pacific. Retrieved September 25, 2012, from http://www.nytimes.com/2009/11/29/world/asia/29babies.html?pagewanted=all

Glendinning, R., \& Howard, R. (2007). Professional English in use: Medicine. Cambridge: Cambridge University Press.

Grice, H. P. (1975). Logic and conversation. NY: Dickenson Publishing Company, Inc.

Hasler, J. (1983). The consultation and postgraduate general practice training. In D. Pendleton, \& J. Hasler (Eds.) (1983), Doctor-patient communication (pp. 249-257). London: Academic Press.

Henley, J. (2011, 1 February). Rupert Whitaker: 'We have to see patients as people, not collections of diseases'. The $\begin{array}{lllll}\text { Guardian. } & \text { Retrieved } & \text { August } & \text { 2012, }\end{array}$ http://www.guardian.co.uk/lifeandstyle/2011/feb/01/rupert-whitaker-urges-patient-power

Hull, M. (2010). Medical English clear \& simple. Philadelphia: F. A. Davis Company.

Kim, Y. K., Hwang, S. Y., \& Shin, S. J. (2011). Analysis of qualitative research published by Korean Journal of Adult Nursing (1989-2011). Korean Journal of Adult Nursing, 23(6), 633-641.

Koreabrand.net. (2010). World in Korea: What is the percentage of foreigners in Korea's population now? Retrieved September 26, 2012, from http://www.koreabrand.go.kr/en/know/know_view.do?CATE_CD=0003\&SEQ=274 
Lee, Hwa-jin. (2008). An analysis of nurses' behavior for politeness in cancer patient-centered conversation. Korean Journal of Adult Nursing, 20(5), 743-754.

Lee, Hwa-jin. (2011). Nurses' question and explanation strategies for effective communication with cancer patients. Journal of the Korean Academy of Fundamental Nursing, 18(2), 247-257.

Ley, P. (1983). Patient's understanding and recall in clinical communication failure. In D. Pendleton, \& J. Hasler (Eds.) (1983), Doctor-patient communication (pp. 89-107). London: Academic Press.

Lu, P-Y, \& Corbett, J. (2012). English in medical education: An intercultural approach to teaching language and values (Languages for intercultural communication). Bristol: Multilingual Matters.

McCullagh, M. (2008). Good practice Student's Book: Communication skills in English for the medical practitioner. Cambridge: Cambridge University Press.

Morasch, L. J. (2004). "I hear you talking, but I don't understand you!": Medical jargon \& clear communication. Monograph based on a roundtable discussion hosted by Martha Bernadett, MD, MBA of Molina Healthcare as part of Hablamos Juntos, a project funded by The Robert Wood Johnson Foundation: Molina Health Care and California Academy of Family Physicians. Retrieved September 25, 2012, from http://www.familydocs.org/assets/Multicultural_Health/MedicalJargon.pdf

Morrison, P., \& Burnard, P. (2007). Caring and communicating: The interpersonal relationship in nursing. London: Macmillan.

Parkinson, J. (2004). Everyday English for international nurses: A guide to working in the UK. London: Churchill Livingstone.

Pendleton, D., \& Wakeford, R. (1979). A communication skills course for new clinical students. Paper presented at the Annual Meeting of the Association for the Study of Medical Education, University of Southampton.

Regan, L. (2007). Doctor, doctor jokes. Woodbridge, U.K.: Top That! Publishing PLC.

Richards, T. (1990). Chasms in Communication. British Medical Journal, 301, 1407. http://dx.doi.org/10.1136/bmj.301.6766.1407

Schmidt, L. A. (2010). Making sure: registered nurses watching over their patients. Nursing Research, 59(6), 400-406. http://dx.doi.org/10.1097/NNR.0b013e3181faa1c9

Stewart, M. A. (1995). Effective physician-patient communication and health outcomes: A review. Canadian Medical Association Journal, 152(9), 1423-1433.

Tan Jia Xing, J. (2009). The use of therapeutic communication skills in nursing practice. Singapore Nursing Journal, $36(1), 35-40$.

Van Zanten, M. (2011). Evaluating the spoken English proficiency of international medical graduates for certification and licensure in the United States. In B. Hoekje, \& S. Tipton (Eds.) (2011), English Language and The Medical Profession: Instructing and Assessing The Communication Skills of International Physicians (pp. 75-09). Bingley, UK. Emerald Group Publishing Ltd.

Wakeford, R. (1983). Communication skills training in United Kingdom medical schools. In D. Pendleton, \& J. Hasler (Eds.) (1983), Doctor-patient communication. (pp. 233-247). London: Academic Press.

Ward, D. (2009). We nurses never forget that our patients are people. The Guardian. Retrieved August 6, 2012, from http://www.guardian.co.uk/commentisfree/2009/jan/30/nhs-elderly-care

Wachtel, P. L. (2011). Therapeutic communication: Knowing what to say when. New York, NY: The Guilford Press.

\section{Notes}

${ }^{1}$ In this paper, quoted texts preserve the original spelling.

${ }^{2}$ This attitude is similar to that of some native speakers of English who think that because they use the language every day they can teach it to other people without first gaining qualifications in ELT. 